\title{
Activation profile of cGMP-dependent protein kinase l $\alpha$
}

\author{
Sabine Wolter ${ }^{1 *}$, Marina Golombek ${ }^{1}$, Frank Schwede ${ }^{2}$, Hans-Gottfried Genieser ${ }^{2}$, Stefan Dove ${ }^{3}$, Roland Seifert ${ }^{1}$ \\ From 6th International Conference on cGMP: Generators, Effectors and Therapeutic Implications \\ Erfurt, Germany. 28-30 June 2013
}

\section{Background}

cGMP-dependent protein kinase (PKG) is a serine/ threonine kinase which is potently activated by cGMP [1]. PKG is encoded by two genes, forming two different proteins, PKGI and PKGII. The two isoforms of PKGI, PKGI $\alpha$ and PKGI $\beta$, differ in the $\mathrm{N}$-terminal amino acid sequences. PKGI isozymes are homodimers with two identical subunits possessing a catalytic and a regulatory domain each. The regulatory domain contains two nonidentical binding sites for cyclic nucleotides (cNMPs), i.e., a slowly exchanging and a rapidly exchanging site. The activation constant $\left(K_{a}\right)$ of PKGIa for cGMP is about 3-fold lower than the corresponding $\mathrm{K}_{\mathrm{a}}$ of PKGI $\beta$ suggesting distinct physiological roles of the isoforms. In addition to cGMP, other cNMPs and also cNMP analogues activate or inhibit PKG [2-4]. While many investigations focussed on discrimination between the cNMP binding sites by employing cGMP and cAMP analogues, little is known about interaction of PKGI $\alpha$ with cCMP analogues or with $R p$ - and $S p$ - diastereomers of cCMP phosphorothioates.

As was shown by Desch et al. [5], the membrane-permeable cCMP analogue dibutyryl-cCMP (DB-cCMP) induces smooth muscle relaxation and activates PKGI in aortic tissue lysates. Therefore, we have studied 4-MB-cCMP, the resulting active metabolite after cleavage of DB-cCMP by esterases, and also corresponding substances from cAMP and cGMP, on purified PKGI $\alpha$.

\section{Materials and methods}

PKG kinase activity was measured in-vitro by a radiometric kinase assay in the presence of cGMP or different cNMP analogues. $\mathrm{pEC}_{50}$ values, $\mathrm{K}_{\mathrm{a}}$, Hill slopes and $\mathrm{E}_{\max }$ values were calculated using GraphPad Prism software.

\footnotetext{
* Correspondence: wolter.sabine@mh-hannover.de

${ }^{1}$ Institute of Pharmacology, Hannover Medical School, Hannover, Germany Full list of author information is available at the end of the article
}

$E_{\max }$ values were related to $E_{\max }$ values of the activation of PKGI $\alpha$ by cGMP, which was set to 1.00 .

\section{Results and discussion}

Besides the known activator cGMP, many other cNMPs and cNMP analogues are activators of PKGI $\alpha$, with distinct activation constants $\left(\mathrm{pEC}_{50}\right)$, specific Hill slopes and different maximal effects $\left(E_{\max }\right)$ (Table 1$)$. The most potent and effective activator for PKGI $\alpha$ was cGMP. The active metabolite of DB-cGMP, 2-MB-cGMP was less potent and effective.

cAMP and 6-MB-cAMP showed similar potency, but 6-MB-cAMP had a higher efficacy than cAMP. 4-MBcCMP was a more effective activator than cCMP, but showed a reduced potency.

Table $1 \mathrm{pEC}_{50}, \mathrm{~K}_{\mathrm{a}}$, Hill slopes and $\mathrm{E}_{\max }$ for the activation of PKGI $\alpha$ by cNMPs.

\begin{tabular}{|c|c|c|c|c|}
\hline cNMP & $\mathrm{pEC}_{50}$ & $\mathrm{~K}_{\mathrm{a}}(\mu \mathrm{M})$ & Hill slope & $E_{\max }$ \\
\hline cGMP** & $6.98 \pm 0.04$ & 0.11 & $1.71 \pm 0.36$ & $1.00 \pm 0.04$ \\
\hline 2-MB-cGMP & $5.84 \pm 0.13$ & 1.45 & $1.12 \pm 0.34$ & $0.66 \pm 0.03$ \\
\hline CAMP** & $4.82 \pm 0.11$ & 15.13 & $1.28 \pm 0.39$ & $0.59 \pm 0.05$ \\
\hline 6-MB-сAMP & $4.67 \pm 0.06$ & 21.38 & $1.35 \pm 0.19$ & $0.81 \pm 0.03$ \\
\hline CCMP** & $4.58 \pm 0.14$ & 26.30 & $1.84 \pm 0.53$ & $0.55 \pm 0.04$ \\
\hline 4-MB-cCMP & $4.05 \pm 0.10$ & 89.13 & $1.10 \pm 0.23$ & $0.71 \pm 0.06$ \\
\hline Sp-cAMPS & $3.72 \pm 0.61$ & 190.55 & $1.38 \pm 2.86$ & $0.16 \pm 0.01^{*}$ \\
\hline Rp-cAMPS & n.d. & n.d. & n.d. & n.d. \\
\hline Sp-cCMPS & $3.53 \pm 0.97$ & 295.12 & $1.11 \pm 1.34$ & $0.17 \pm 0.02^{*}$ \\
\hline Rp-cCMPS & n.d. & n.d. & n.d. & n.d. \\
\hline CIMP** & $4.72 \pm 0.04$ & 19.05 & $1.54 \pm 0.16$ & $0.87 \pm 0.02$ \\
\hline CUMP** & $4.15 \pm 0.04$ & 70.79 & $0.85 \pm 0.21$ & $0.72 \pm 0.03$ \\
\hline CXMP** & $3.98 \pm 0.04$ & 104.71 & $2.06 \pm 1.93$ & $0.69 \pm 0.03$ \\
\hline
\end{tabular}

*: value shows the maximum activation with $3 \mathrm{mM}$ cNMP without saturation of the concentration/response curve

**: data from Wolter et al, Biochem Biophys Res Commun. 2011, 415: 563-566. n.d.: not determinable because of lack of saturation of the concentration/ response curve.

\section{() Biomed Central}


The cNMP analogues activated PKGI $\alpha$ in the order of potency cGMP > 2-MB-cGMP > cAMP > 6-MB-cAMP $>$ cCMP $>4-\mathrm{MB}-\mathrm{cCMP}$ and in the order of efficacy cGMP > 6-MB-cAMP > 4-MB-cCMP > 2-MB-cGMP > cAMP > cCMP.

$R p$-cAMPS and $R p$-cCMPS did not activate PKGI $\alpha$. The stable phosphorothioates $S p$-cAMPS and $S p$-cCMPS activated PKGI $\alpha$ only at high concentrations in the order of potency and efficacy cGMP > cAMP > cCMP > $S p$-cAMPS $\sim S p$-cCMPS.

Furthermore, we illustrate binding of cNMPs for PKG based on existing crystal structures and discuss current problems with respect to molecular modelling approaches. In conclusion, 4-MB-cCMP is a more effective PKG activator than $\mathrm{CCMP}$ and, therefore, a valuable tool for analysing the second messenger role of cCMP [6].

\section{Authors' details}

${ }^{1}$ Institute of Pharmacology, Hannover Medical School, Hannover, Germany.

${ }^{2}$ Biolog Life Science Institute, Bremen, Germany. ${ }^{3}$ Department of

Pharmaceutical/Medicinal Chemistry II, University of Regensburg,

Regensburg, Germany.

Published: 29 August 2013

\section{References}

1. Hofmann F: The biology of cyclic GMP-dependent protein kinases. J Biol Chem 2005, 280:1-4.

2. Corbin JD, Øgreid D, Miller JP, Suva RH, Jastorff B, Døskeland SO: Studies of CGMP analog specificity and function of the two intrasubunit binding sites of cGMP- dependent protein kinase. J Biol Chem 1986, 261:1208-1214.

3. Butt $E$, van Bemmelen $M$, Fischer $L$, Walter $U$, Jastorff $B$ : Inhibition of cGMP- dependent protein kinase by $(R p)$-guanosine $3^{\prime}, 5^{\prime}$ monophosphorothioates. FEBS Letters 1990, 263:47-50.

4. Wolter S, Golombek M, Seifert R: Differential activation of CAMP- and cGMP- dependent protein kinases by cyclic purine and pyrimidine nucleotides. Biochem Biophys Res Commun 2011, 415:563-565.

5. Desch M, Schinner E, Kees F, Hofmann F, Seifert R, Schlossmann J: Cyclic cytidine 3',5'-monophosphate (cCMP) signals via cGMP kinase I. FEBS Letters 2010, 584:3979-3984.

6. Beste KY, Seifert R: CCMP, cUMP, CTMP, CIMP and CXMP as possible second messengers: development of a hypothesis based on studies with soluble guanyly I cyclase a1ß2. Biol Chem 2013, 394:261-270.

doi:10.1186/2050-6511-14-S1-P79

Cite this article as: Wolter et al:: Activation profile of cGMP-dependent protein kinase I $\alpha$. BMC Pharmacology and Toxicology 2013 14(Suppl 1):P79.

\section{Submit your next manuscript to BioMed Central} and take full advantage of:

- Convenient online submission

- Thorough peer review

- No space constraints or color figure charges

- Immediate publication on acceptance

- Inclusion in PubMed, CAS, Scopus and Google Scholar

- Research which is freely available for redistribution

Submit your manuscript at www.biomedcentral.com/submit
C Biomed Central 